\title{
Epoxidized natural rubber toughened polylactic acid/talc composites: mechanical, thermal, and morphological properties
}

\begin{abstract}
The aim of present study is to develop a toughened polylactic acid/talc composite. Talc and epoxidized natural rubber (ENR-50) were compounded with polylactic acid using counterrotating twin-screw extruder followed by preparation of samples through injection molding. The effect of silane-treated talc and epoxidized natural rubber on mechanical, thermal, and morphological properties of polylactic acid was investigated. The Young $\mathbb{N} \mathbf{j}$ and flexural modulus of polylactic acid improved while the impact strength values dropped with increasing talc content $(20 \ddot{3} 30 \mathrm{Wt} / \%)$ indicating that talc increased the stiffness of polylactic acid with a sacrifice in toughness. Subsequently, the blending of epoxidized natural rubber (20 t $\%$ ) to polylactic acid/talc $(30$ th $\%$ ) revealed that the impact strength of polylactic acid/talc composites improved $448 \%$ with considerable drop in Youngô and flexural modulus. Polylactic acid/talc/epoxidized natural rubber composite contains $60 \%$ polylactic acid, $30 \mathbb{W} \mathrm{t} \%$ talc, and $10 \mathbb{W} \mathrm{t} \%$ ENR display optimum stiffness and impact strength. Scanning electron micrographs demonstrates that talc agglomerates at higher loadings. Thermogravimetric anlaysis indicated that thermal stability of polylactic acid/talc composite was reduced by the addition of epoxidized natural rubber due to increasing talc agglomeration.
\end{abstract}

Keyword: Polylactic acid; Talc; Epoxidized natural rubber; Mechanical properties; Thermal properties 